\title{
ROSTROS DE OTRA PARTE
}

\section{FACES FROM ANOTHER PLACE}

\section{Páginas Andrés Felipe Restrepo}

130-132 afrestrep@gmail.com

Artista plástico de la Universidad Nacional de Colombia, sede Medellín. Ganador del Premio Nacional a la Memoria (2013), otorgado por el Centro Nacional de Memoria Histórica, con dos obras: IN-HUMUS y Llanto en el río. 
Resumen

Ad portas del fin del conflicto entre el Estado colombiano y las farc, este trabajo presenta los rostros de combatientes que pronto serán desmovilizados. La idea es retar los estereotipos reinantes sobre los insurgentes que sólo pueden representarlos como monstruos desprovistos de toda humanidad para, en cambio, mostrar que son gente común y corriente. Las fotografías tendrán que hablar por sí solas.

\section{Palabras clave}

Colombia, proceso de paz, fotografía-documental, postconflicto, FARC

\section{Abtract}

Taking into account that the end of the conflict between the Colombian State and FARC is just around the corner, this article exposes those faces of the combatants who are soon leaving the warpath. The approach of this paper relies on challenging stereotypes people have of insurgents. Stereotypes that present them as monsters with no human feelings. This texts intends to expose their true nature: people forced to take justice by their own hand. Pictures do the entire talking by themselves.

\section{Key words}

Colombia, Peace Process, Doc-Photography, Postconflict, FARC

\section{Resomo}

Ad porta do fim do conflito entre o Estado colombiano e as FARc, este trabalho apresenta os rostos de combatentes que cedo serão desmovilizados. A ideia é retar os estereotipos reinantes sobre os insurgentes que só podem os representar como monstros desprovistos de toda humanidade para, em mudança, mostrar que são gente comum e corrente. As fotografias terão que falar por si sozinhas.

\section{Palavras-chave}

Colômbia, processo de paz, fotografia-documentária, pós conflito, FARC 
Ellos creen que no hablo porque soy como un bebé, pero no lo soy. Soy como un anciano y ustedes como unos niños, porque yo he peleado en la guerra, $y$ ustedes ni siquiera saben lo que es la guerra. Vi cosas terribles e hice cosas terribles. Si les cuento me pondré triste y ustedes se pondrán tristes.

En esta vida sólo quiero ser feliz. Si les cuento creerán que soy una especie de bestia o demonio. Soy todas esas cosas, pero una vez también tuve una madre, un padre, un hermano y una hermana. Ellos me amaban.

Fragmento final de la película Beasts of No Nation

\section{Historias de la guerra que no todos vivimos}

Cómo no sentir miedo. He estado en partes del país consideradas "zonas rojas» - como Urabá, parte de los Santanderes, Boyacá, etc.-, pero no imaginé llegar hasta San Vicente del Caguán. Nunca, a lo largo de mi vida, he escuchado una noticia sobre esa región que no me causara terror; además, durante casi dos semanas, iba a estar entre las FARc, el catalogado grupo «terrorista». Tuve que esconder a mis amigos el destino de mi viaje para así evitar ser llamado guerrillero. De donde yo vengo la persona de izquierdas es guerrillero, también el que no comparte las ideas del Gobierno.

En Colombia, la posibilidad que han tenido los campesinos o combatientes de las insurgencias de contar sus historias frente a las historias oficiales ha sido nula. Quienes controlan el poder seleccionan sucesos e interpretan la historia de tal forma que concuerden con su ejercicio del mismo y lo legitimen, lo que silencia las voces de víctimas y de excluidos, y condena la otra visión al olvido oficial.
Es menester escuchar la otra historia. Por consiguiente, la recuperación de la memoria histórica no se convierte sólo en una experiencia de catarsis, sino en un ejercicio que da significado a los sucesos vividos individualmente o de forma colectiva. Y así se los comprende, se los explica y se les da sentido.

Más allá de la guerra, somos seres humanos con capacidad de elección, pero las condiciones de vida nos llevaron o nos obligaron a tomar partido en un conflicto. Es imposible contar la historia de cada uno de los combatientes de la guerra en Colombia. Pero puedo contar la de Ansisar, Sol, Jon, Peter, Yuli, entre otros, quienes son el reflejo de una sociedad aparte. Ellos son parte de una Colombia donde sólo se hace presencia con botas y armas. Una Colombia en la que sus deseos de infancia fueron cortados de raíz.

Mi trabajo no pretende justificar el accionar de los grupos armados. Sería ilógico desconocer el actuar de éstos por más de cincuenta años. Sería abandonar las crónicas del pasado y hacerlas a un lado. Únicamente busco mostrar que, aunque sus miembros han sido victimarios, no podemos dejar de reconocer que también son víctimas. Que no son los monstruos que la historia reciente del país nos ha querido mostrar.

Como me decía un indígena del pueblo tama en el Caquetá: «Desde la conquista nosotros los indígenas hemos sido hijos de la guerra». Pretendo aquí recoger esa memoria colectiva, busco contar otra versión de la historia.

\section{Referencias}

Fukunaga, C. (Dirección). (2015). Beasts of No Nation [Película]. 



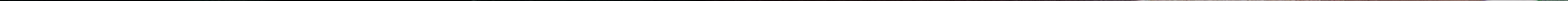




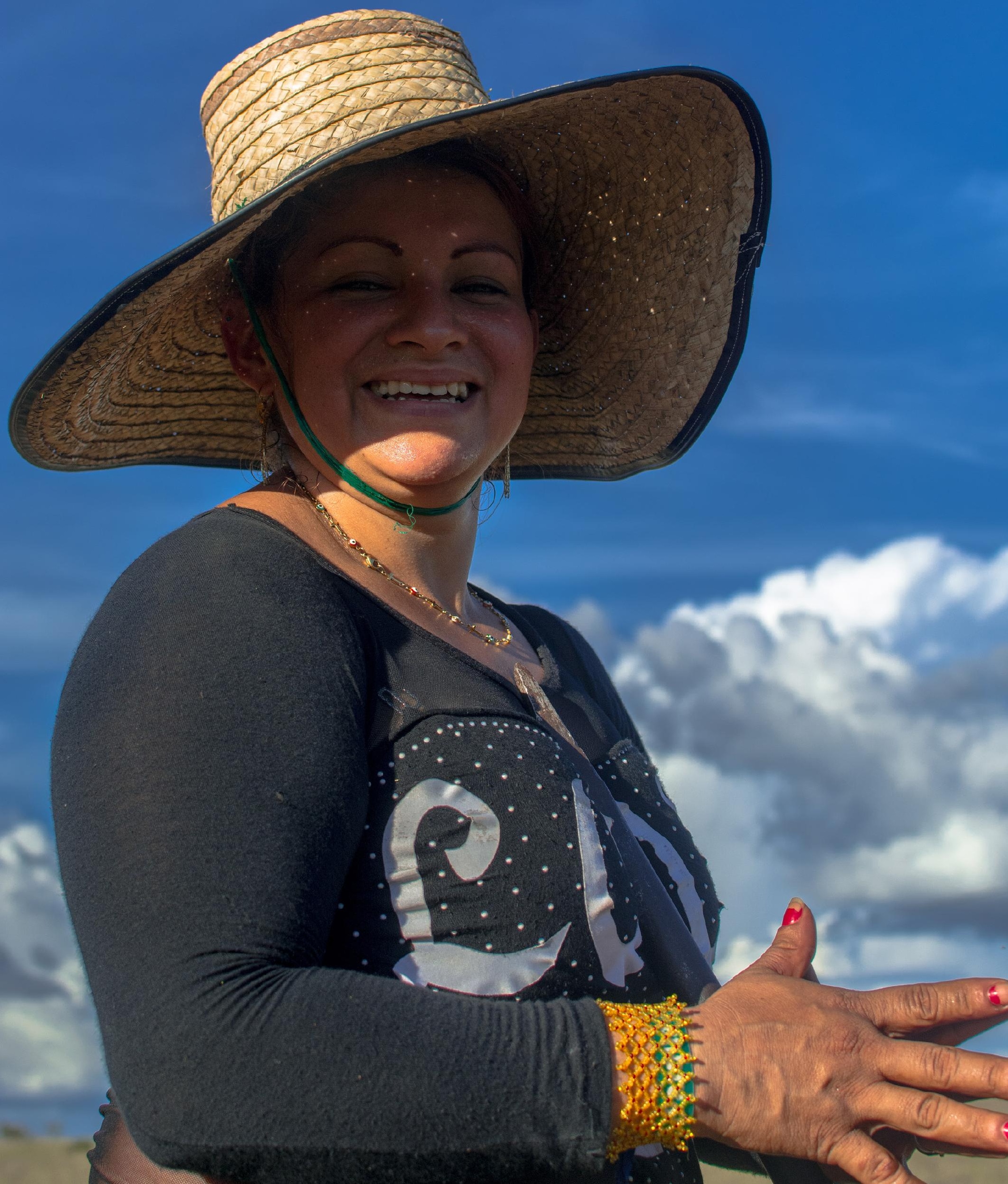




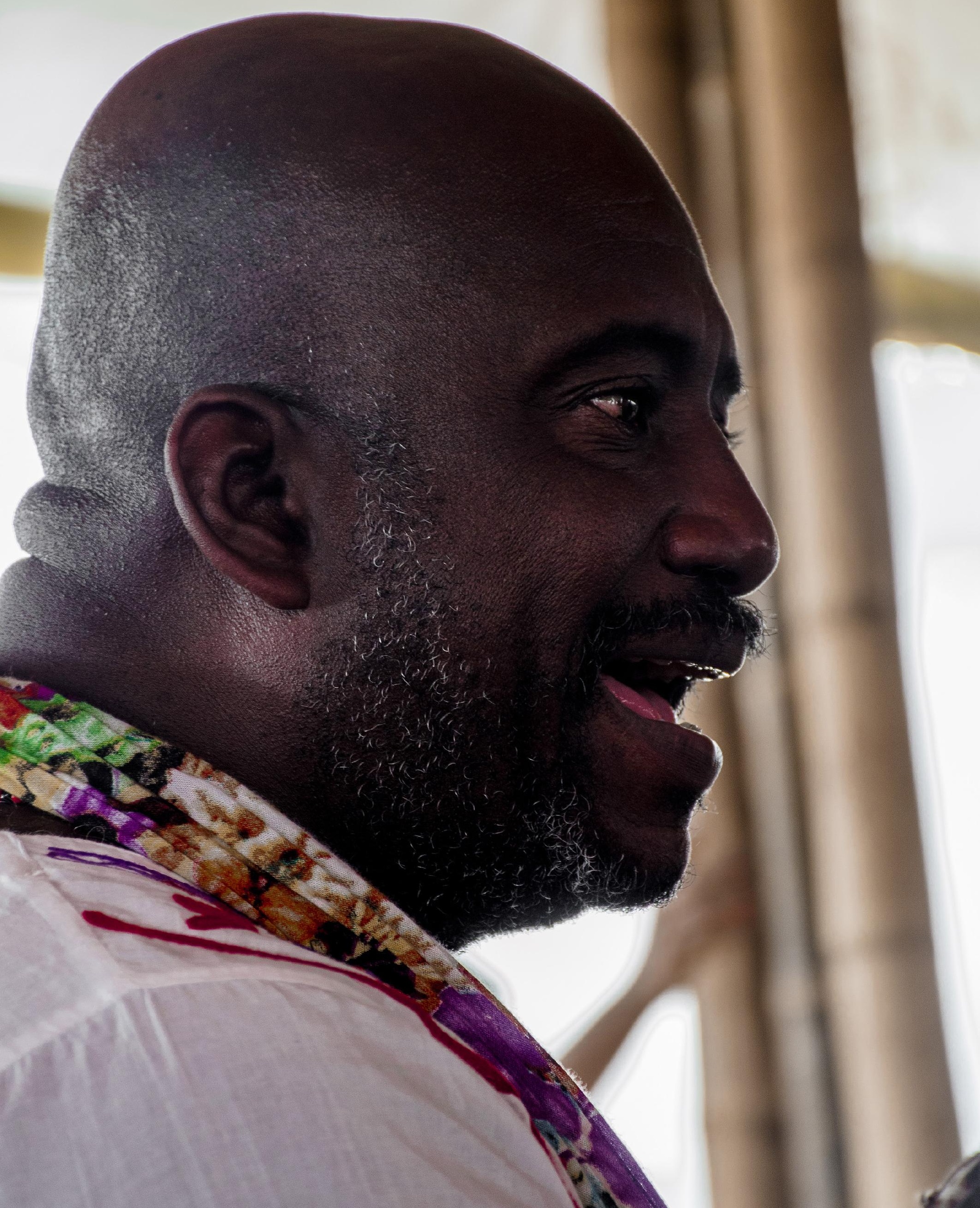




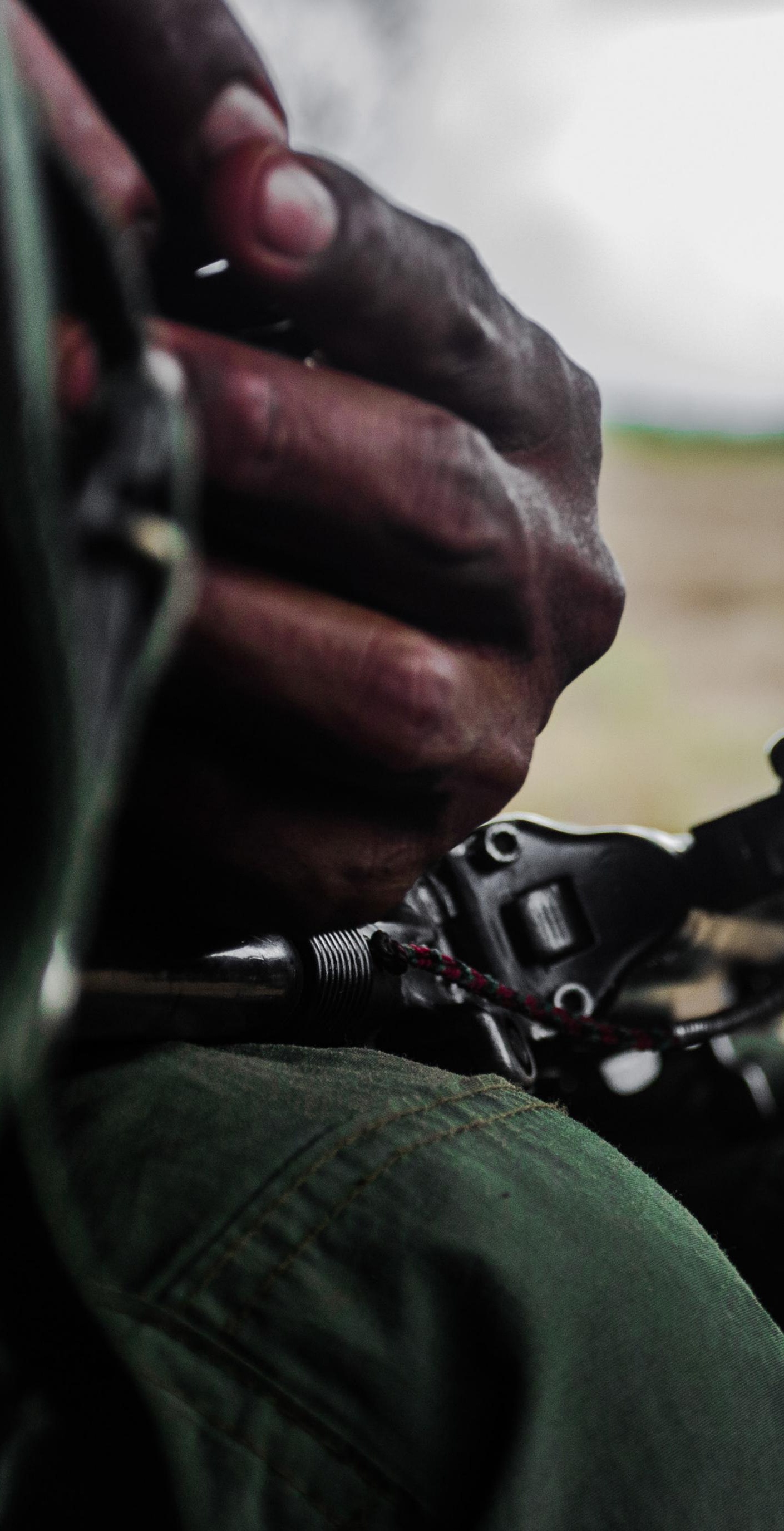




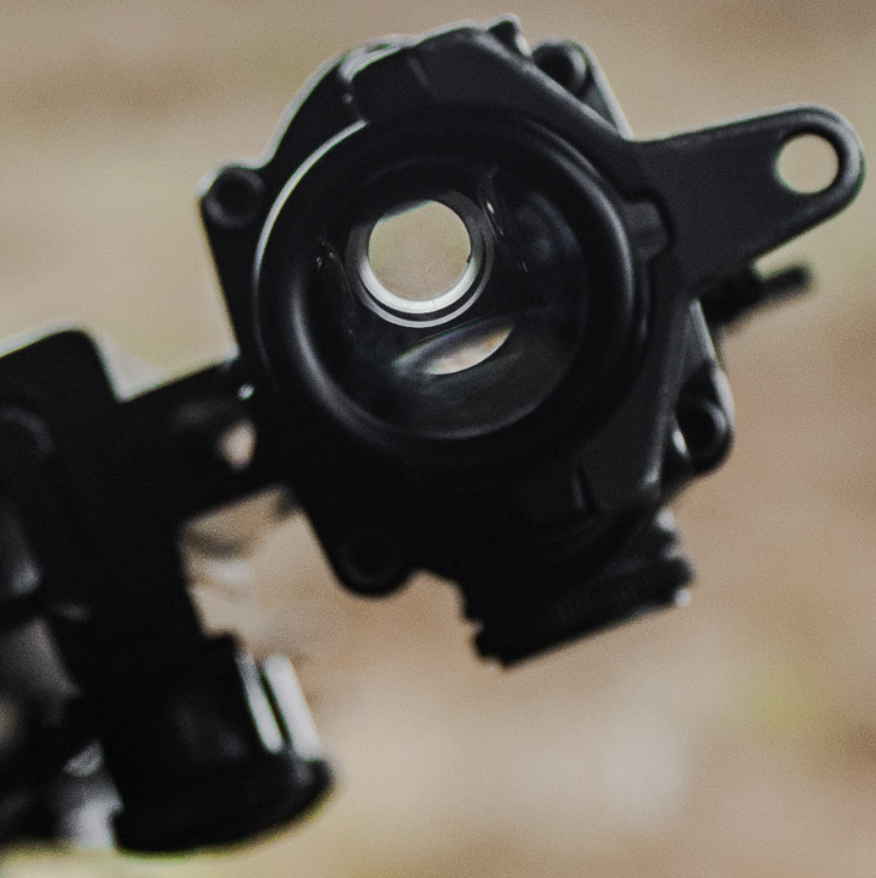




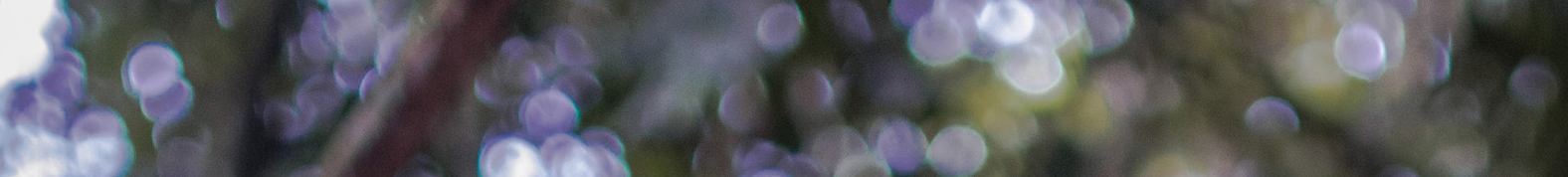
50 ? - 3900 .

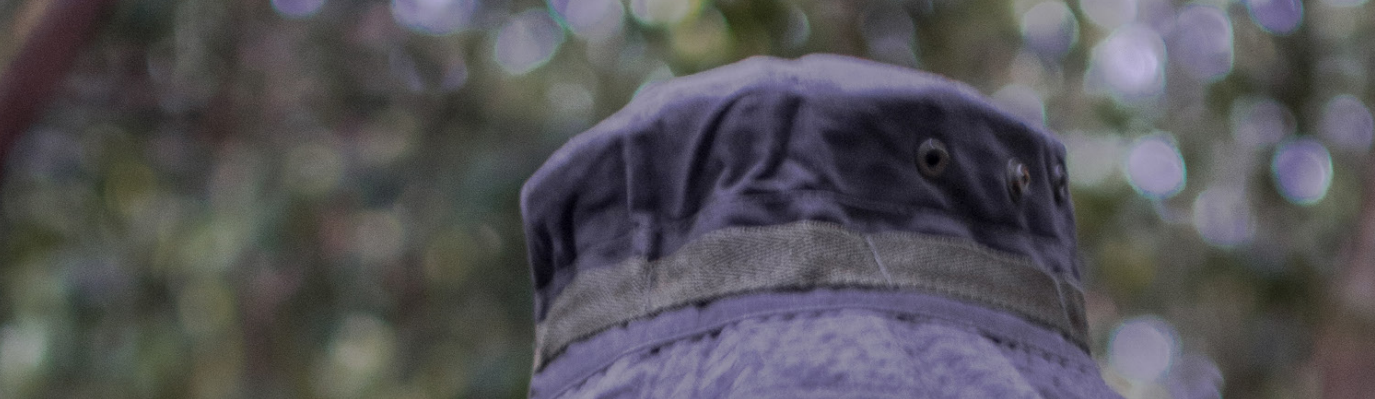
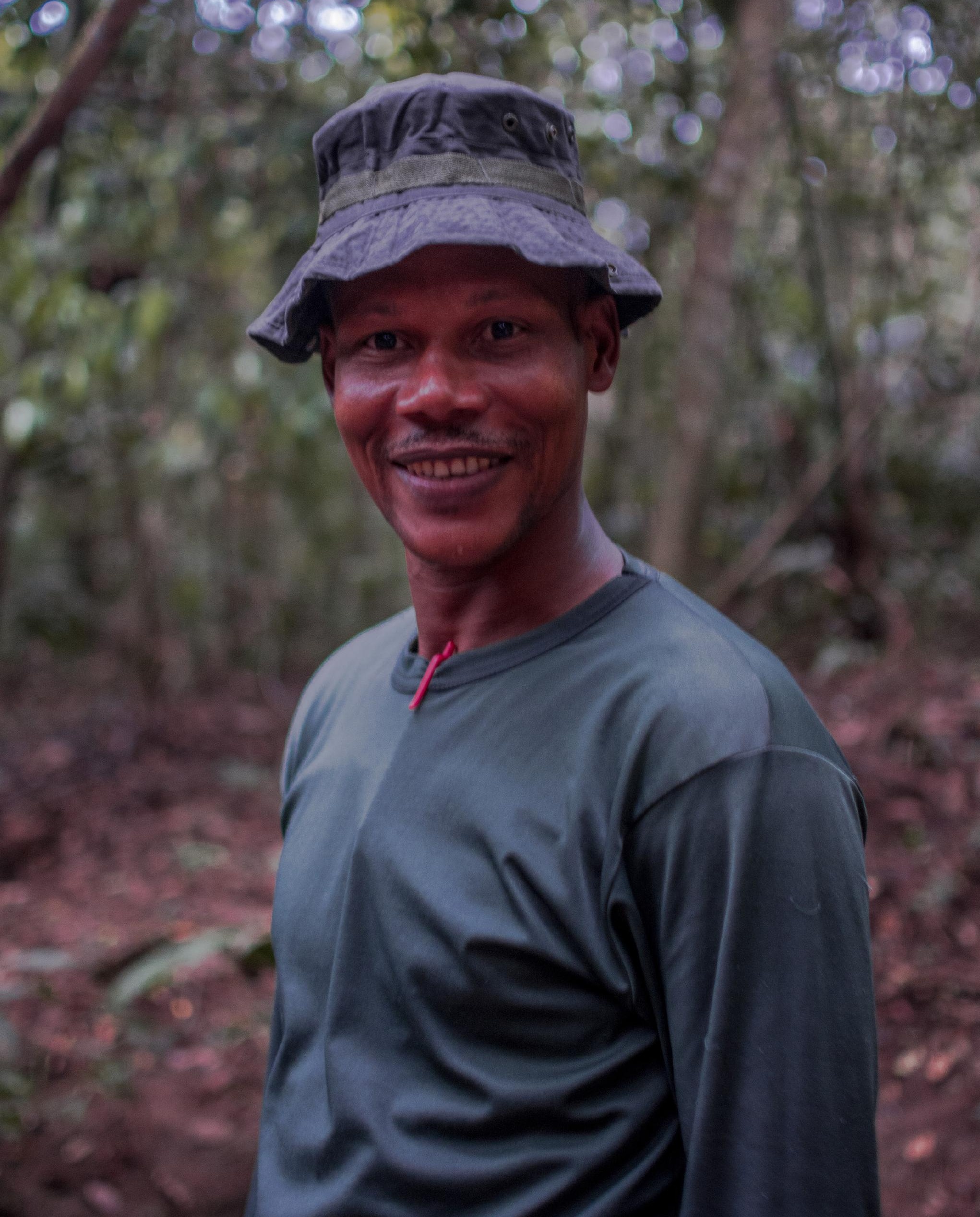

38
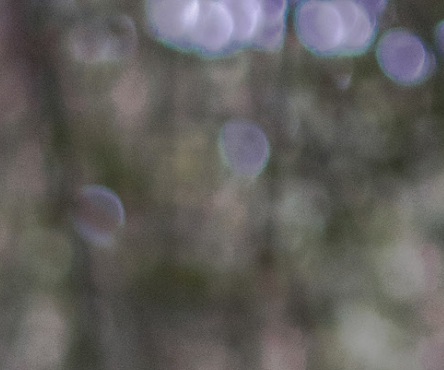


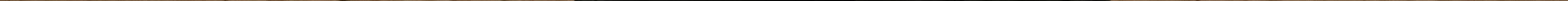




\section{3.}

$=$ sentarits
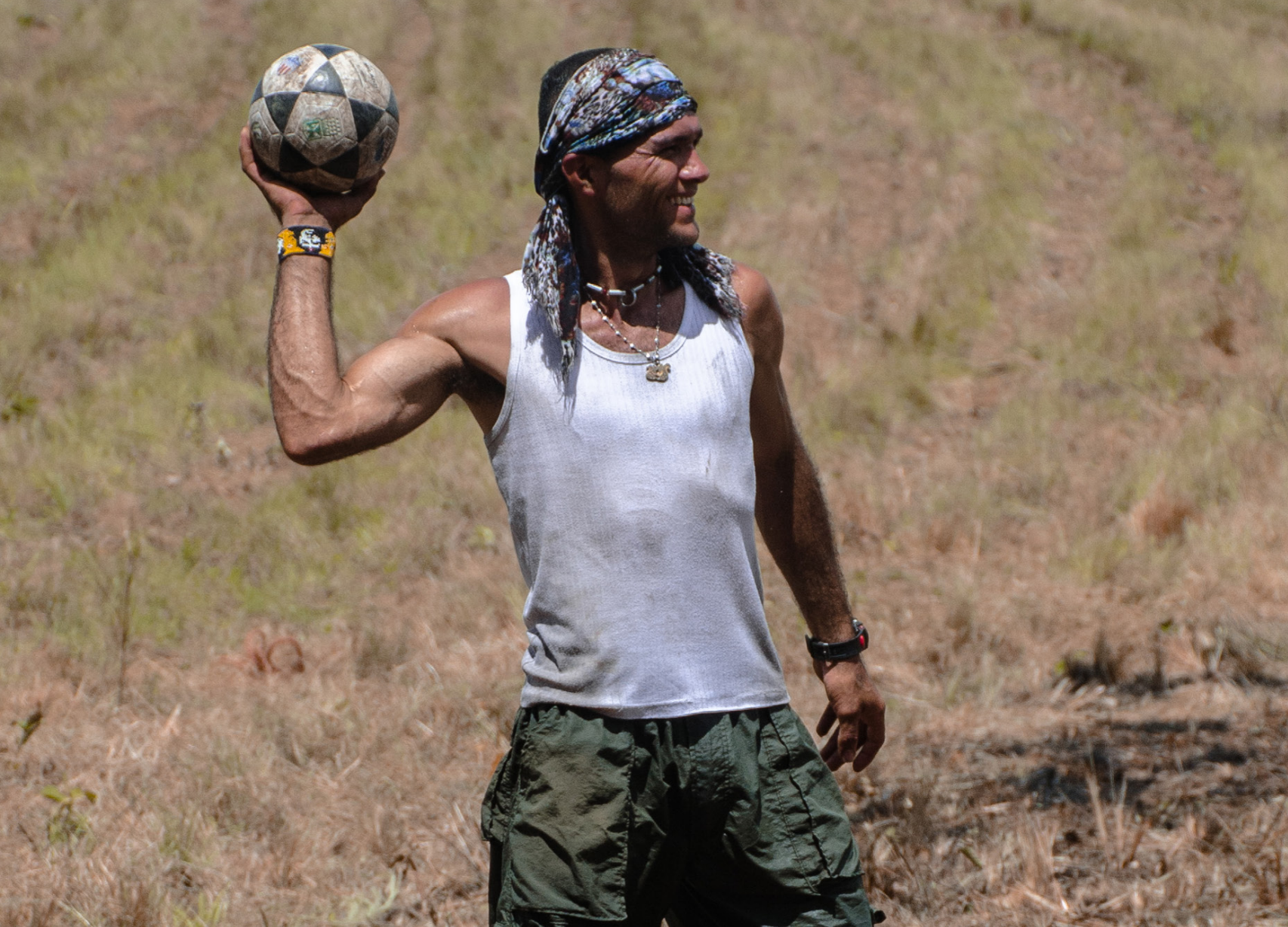

6.

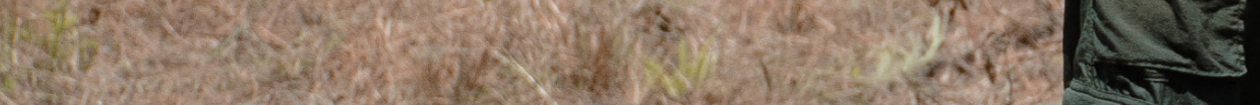

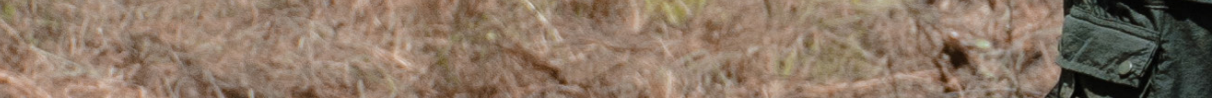
$2,+2 x+2 x+2$

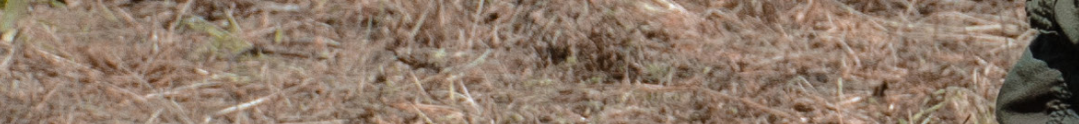
$x^{2}+2+2 y$

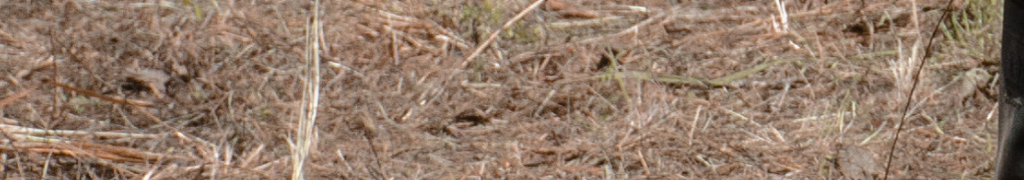

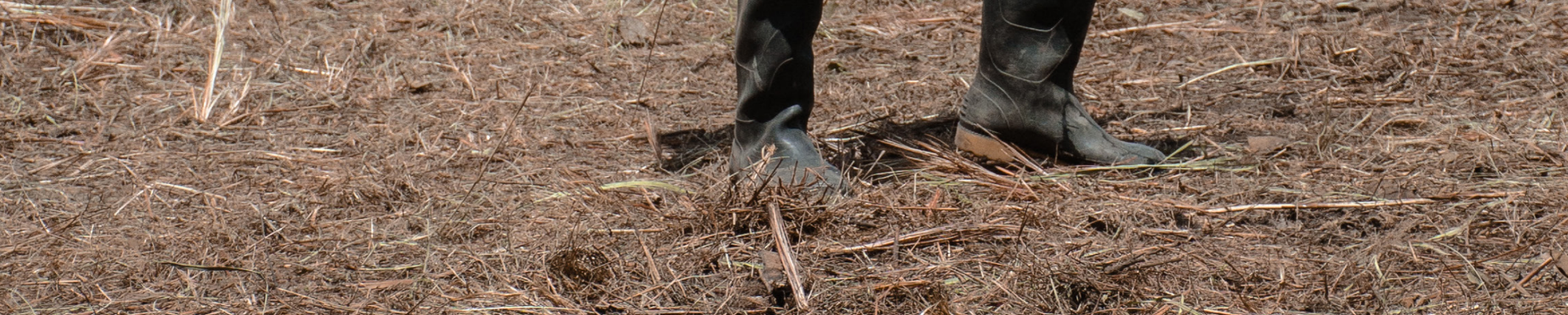

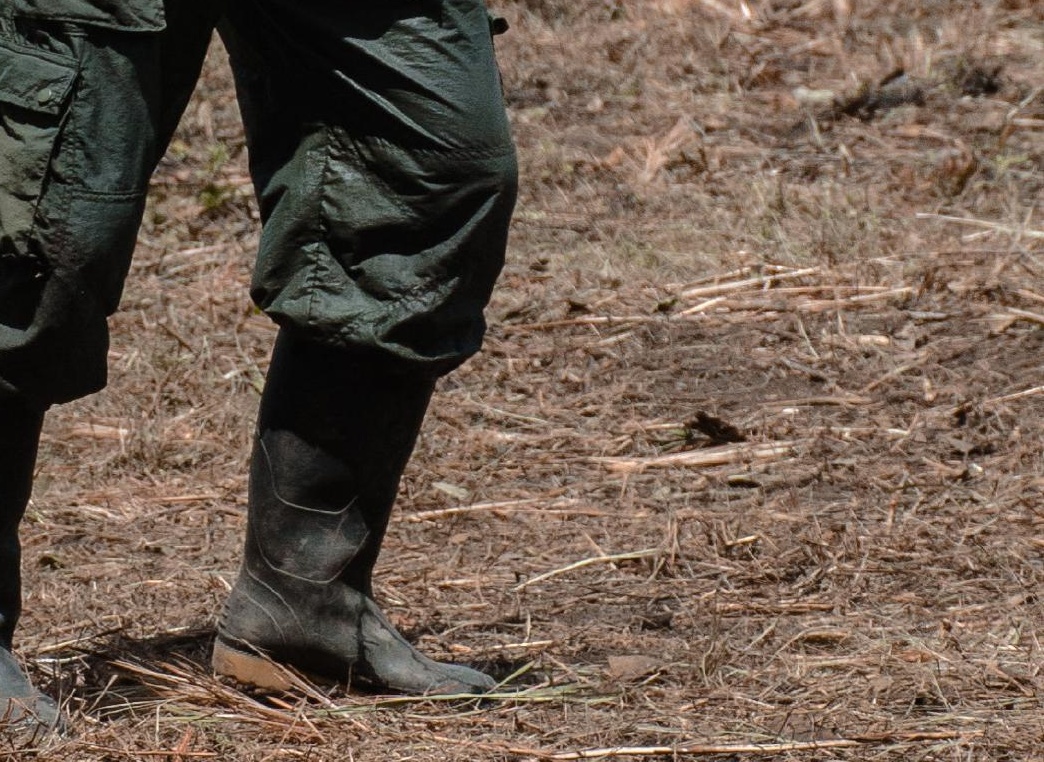

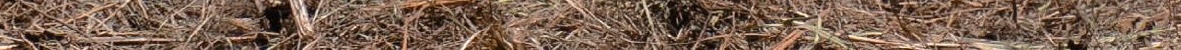




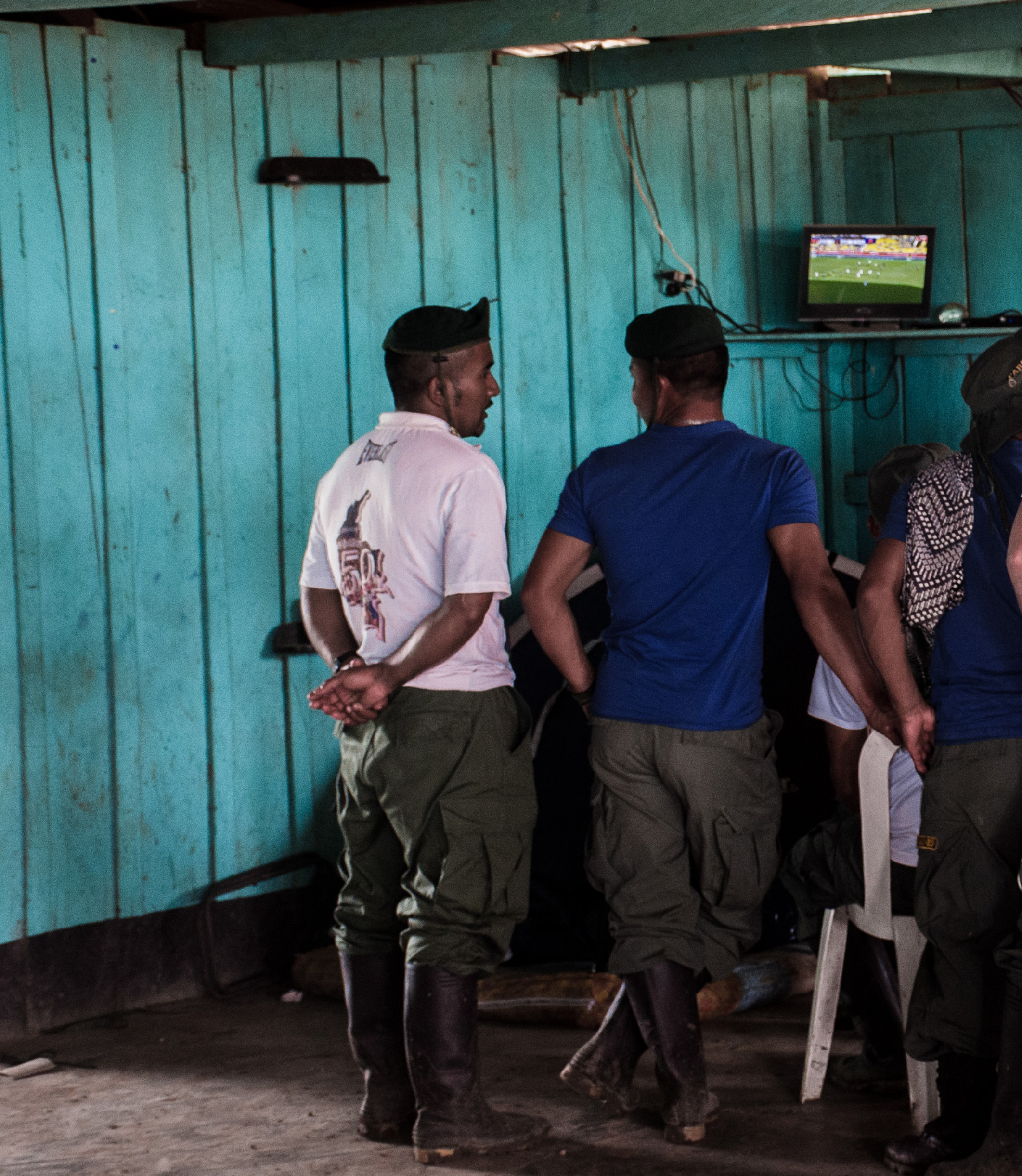




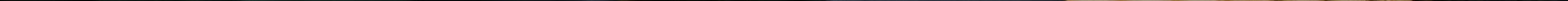




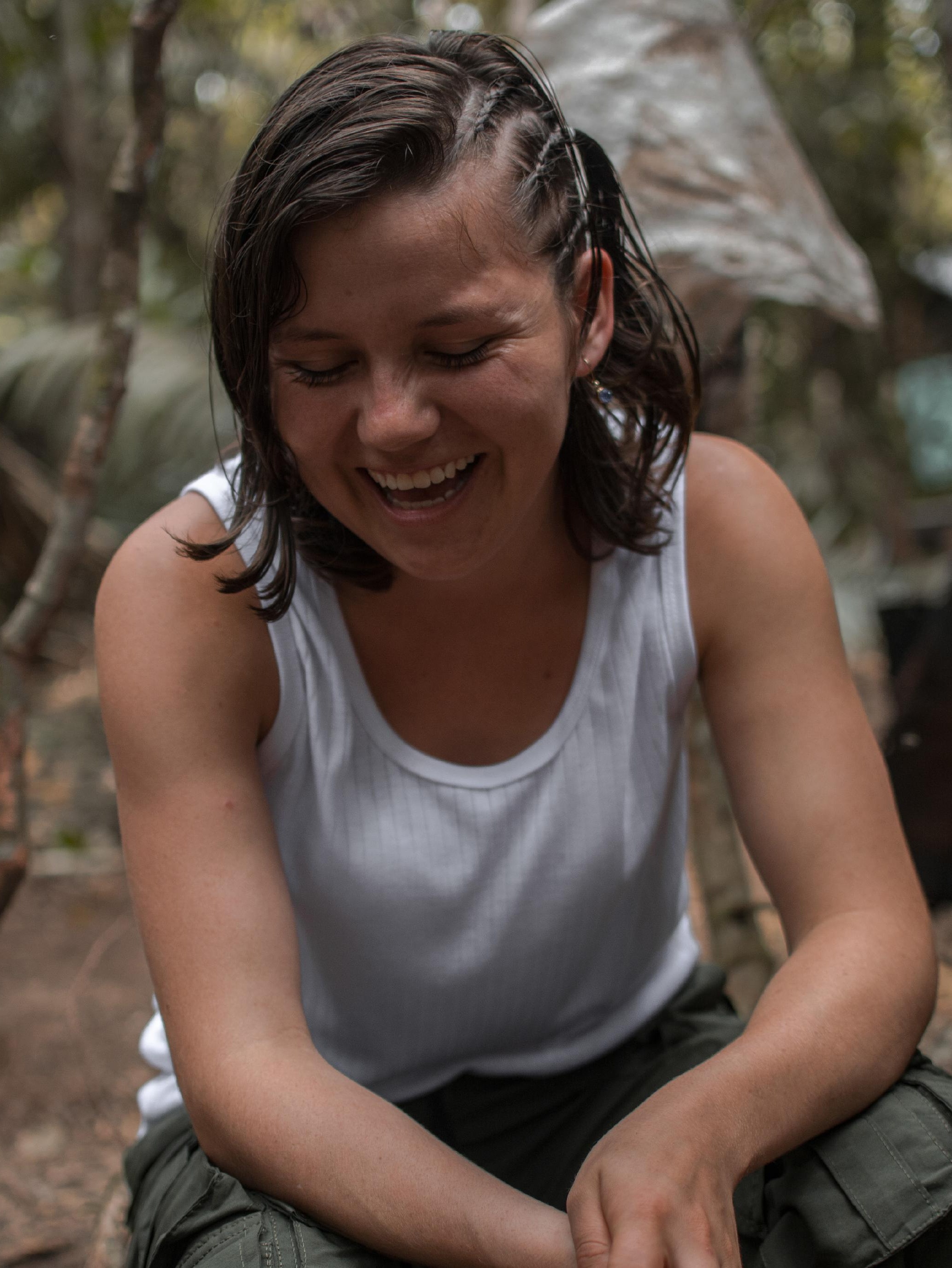




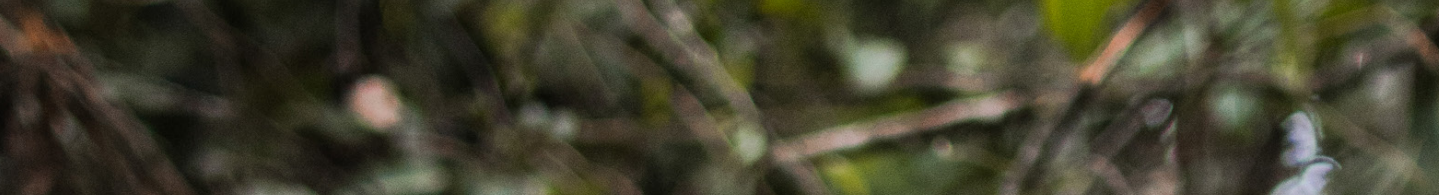

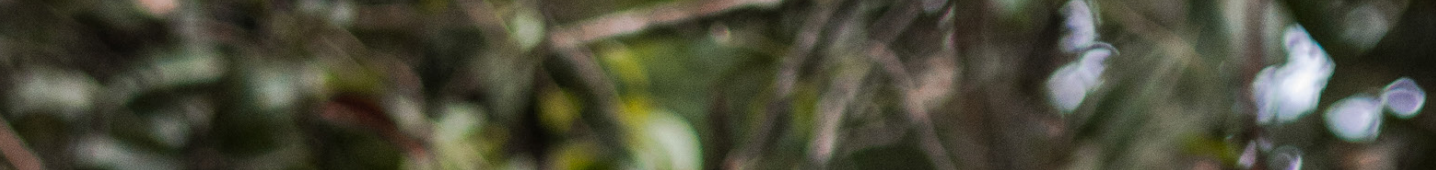

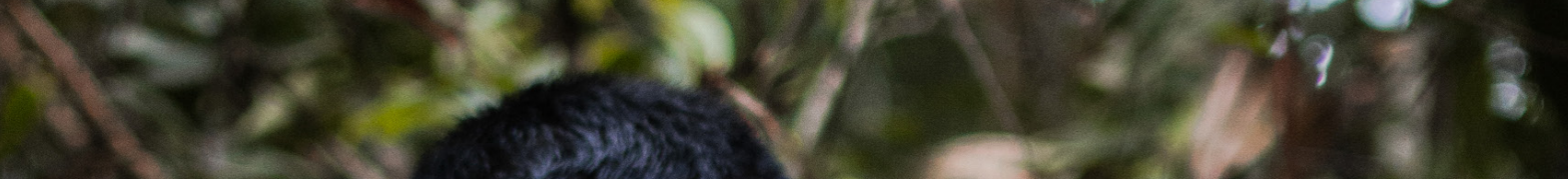
$2030 y+2 x$ $\sin 2$ $\mathcal{H}$
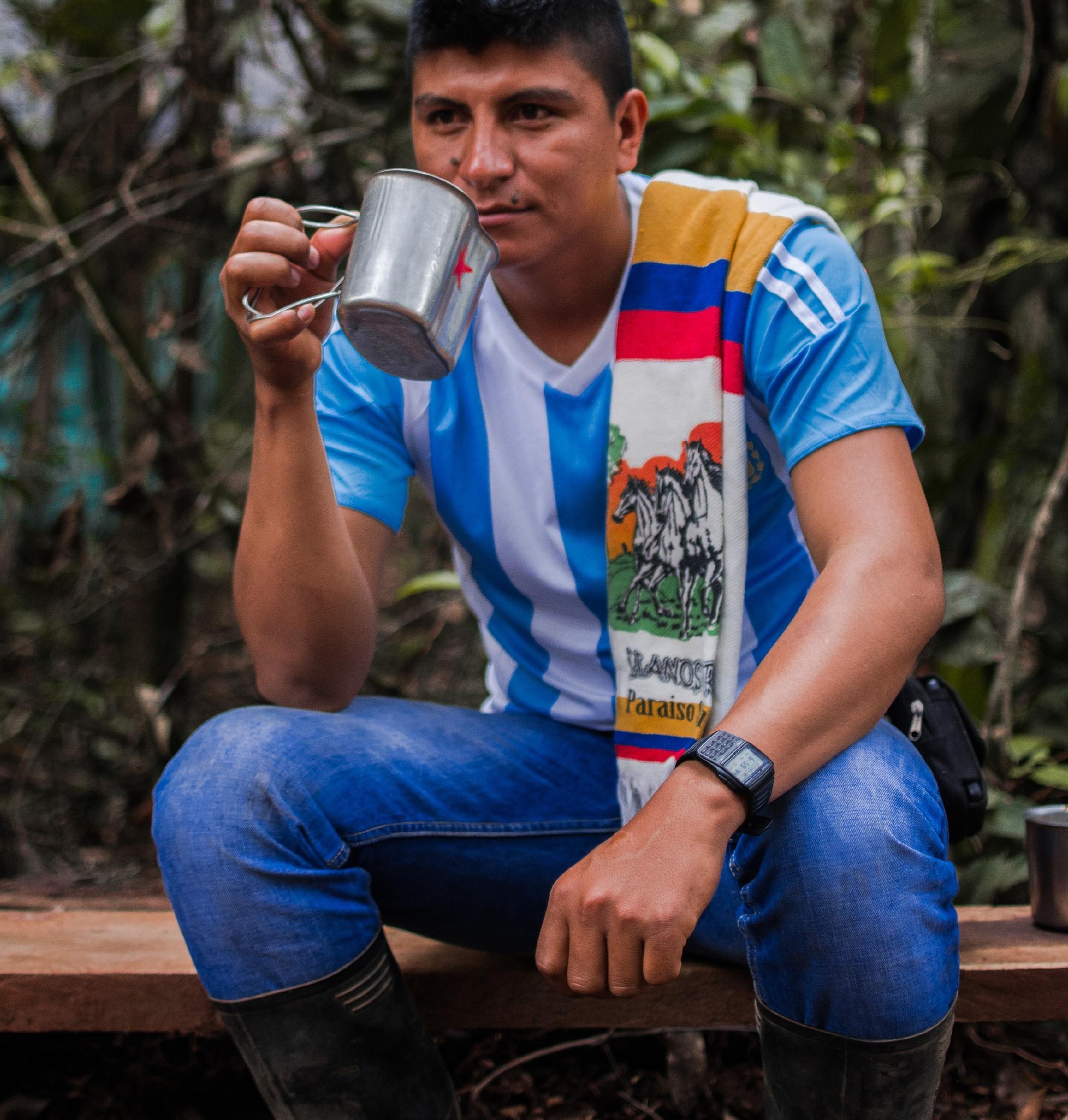

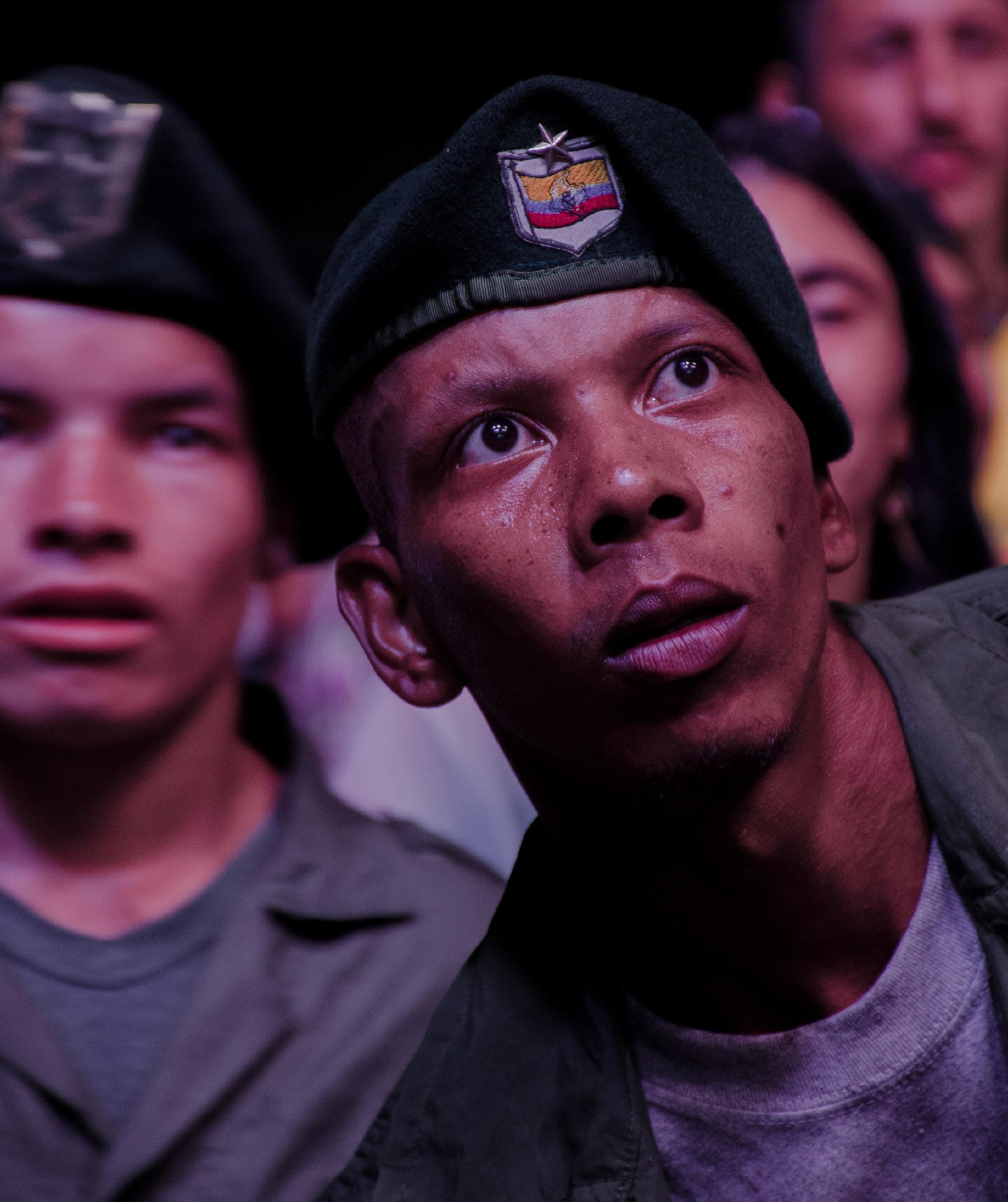


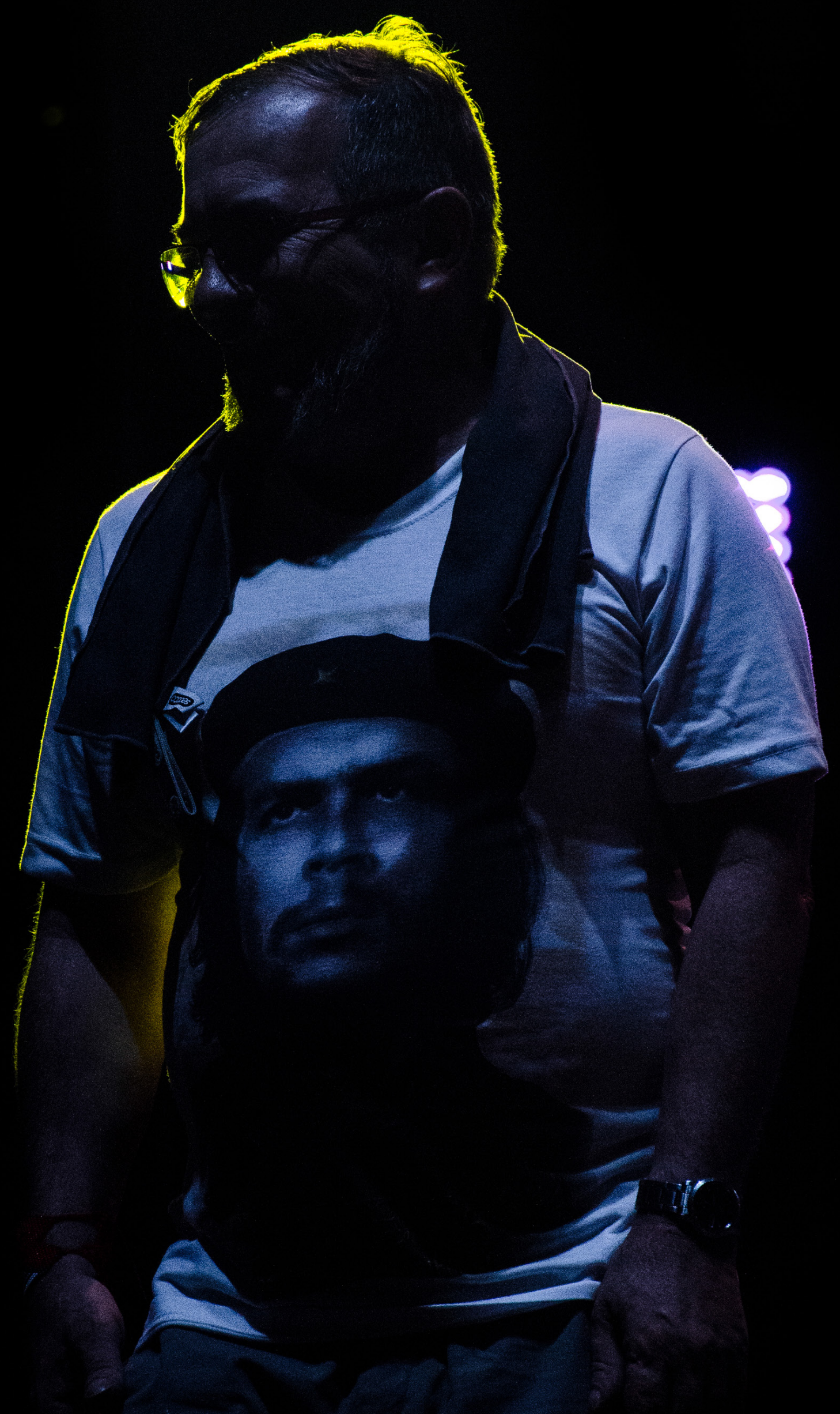

